\title{
Evaluating Suppliers for Healthcare Centre using Ordinal Priority Approach
}

\author{
Tawiah Kwatekwei Quartey-Papafio ${ }^{1}$ | Islam Shajedul ${ }^{2, *} \mid$ Amir Rahimzadeh Dehaghani ${ }^{3}$ \\ ${ }^{1}$ College of Economics and Management, Nanjing University of Aeronautics and Astronautics, Nanjing, China \\ ${ }^{2}$ School of Business, Nanjing University of Information Science and Technology, Nanjing, China \\ ${ }^{3}$ Department of Industrial Engineering, South Tehran Branch, Islamic Azad University, Tehran, Iran \\ *Corresponding author: shajedul@qq.com
}

Received 21 May 2021; Revised 7 July 2021; Accepted 8 July 2021

\begin{abstract}
Supplier selection is one of the most critical problems in the industry. In the healthcare sector, where the tolerance level for mistakes and errors is low, the need to improve the supplier evaluation system is ever increasing. Earlier, the cardinal data-based mathematical models played an important role in supplier selection however since last few decades, the emphasis on the decision-making methods that can handle ordinal relations is gaining exceeding attention. The development of the Ordinal Priority Approach (OPA) is an essential milestone in this regard that is being used in the current study to evaluate the suppliers of a Chinese healthcare facility. The study confirms that the OPA is convenient and powerful approach that can single-handedly estimate the weights of suppliers, criteria and experts. The results demonstrated the feasibility and validity of the approach for healthcare supplier selection problems.
\end{abstract}

Keywords: Ordinal Priority Approach OPA; multi-criteria decision-making MCDM; healthcare; supplier selection

\section{Introduction}

The healthcare industry is an important sector to our day-to-day wellbeing. The functionality and sustainability of the industry always remained a primary societal need. Therefore, a well-equipped healthcare system is required to enable the nation provide necessary medical and health care services (Fan et al., 2020; Javed et al., 2018). Nonetheless, medical commodities and equipment supplies turn to be a significant shortcoming in recent health discussions. A sustainable supply chain by suppliers can play an important role in addressing this situation to achieve economic, social, and environmental gains (Suraraksa \& Shin, 2019). While focusing on the supply chain's best management practices, the healthcare supply chain improved drastically (Saetta \& Caldarelli, 2020). Suppliers of healthcare products are key players in the sector. Therefore, the need to strengthen the supply chain management to ensure sustainability is vital to study.

Because of the increasing importance in real-life, supply chain management and supplier selection remain scholars' focus. Given that, supplier selection has been a sensitive aspect of the supply chain since it has the potential to promote an efficient and sustainable supply chain. Fashoto et al. (2016) argued that to enhance supplier evaluation system, it is advisable to consider several criteria such as delivery, service, quality, price, and risk other than the traditional approach that only relied on cost and/or references in making a decision. The challenges in the supplier section in the healthcare sector 
become barriers for patients' satisfaction and administering a good quality service. The trade-off between cost and other criteria is an important discussion in literature (Reuter et al., 2012); however, supplier evaluation with a focus on price is no more a popular choice, and supplier selection is analysed through multi-criteria decision-making (MCDM) approach is gaining exceeding attention. MCDM method recognizes two or more criteria that are relevant to the subject matter in making analyses. Typical examples of MCDM methods are Analytical Hierarchy Process (AHP) and Technique of Order Preference to Similarity to Ideal Solution (TOPSIS), Grey Relational Analysis (GRA), fuzzy methods, and artificial neural networks. These model techniques have been used in many industries for supplier selection and have yielded satisfactory results. However, each method has its own limitations, and when the problem contains preferential relations and experts are also weighted, these methods may become impractical. The Ordinal Priority Approach is a new development in this regard that has resolved many problems haunting the existing MCDM methodologies, and will be the focus of the current study.

The rest of the study is organized into the following sections. The second section introduces the Ordinal Priority Approach and its computational step. The third section presents research methodology where data collection methodology and data collected is shown, along with the framework of the supplier selection. The fourth section presents the results and discussion. The last section concludes the study with some recommendations.

Table 1. A review of supplier selection in the healthcare sector

\begin{tabular}{|c|c|c|c|}
\hline Year & Description & Methodology & Literature \\
\hline 1997 & $\begin{array}{l}\text { Review of supplier selection } \\
\text { criteria in healthcare setting }\end{array}$ & Qualitative study & Lambert et al. (1997) \\
\hline 2014 & $\begin{array}{l}\text { Sustainable supplier selection } \\
\text { for the medical device industry }\end{array}$ & Fuzzy Inference System (FIS) & Ghadimi and Heavey (2014) \\
\hline 2015 & $\begin{array}{l}\text { Supplier selection in blood } \\
\text { bags manufacturing industry }\end{array}$ & Fuzzy TOPSIS & Venkatesh et al. (2015) \\
\hline 2015 & $\begin{array}{l}\text { Project selection for the } \\
\text { healthcare industry }\end{array}$ & DEMATEL-ANP & Ortíz et al. (2015) \\
\hline 2016 & $\begin{array}{l}\text { Supplier selection in healthcare } \\
\text { sector }\end{array}$ & $\mathrm{AHP}$ and $\mathrm{ANN}$ & Fashoto et al. (2016) \\
\hline 2018 & $\begin{array}{l}\text { Supplier selection for hospital } \\
\text { waste management }\end{array}$ & AHP & Ishtiaq et al. (2018) \\
\hline 2019 & $\begin{array}{l}\text { Evaluation and selection of } \\
\text { supplier for hospital }\end{array}$ & $\begin{array}{l}\text { (i) AHP-TOPSIS } \\
\text { (ii) AHP-ELECTRE } \\
\text { (iii) AHP-GRA } \\
\text { (iv) AHP-SAW }\end{array}$ & Akcan and Güldeş (2019) \\
\hline 2019 & Site selection for new hospital & AHP & Şahin et al. (2019) \\
\hline 2019 & $\begin{array}{l}\text { Supplier selection for hospital } \\
\text { pharmacy }\end{array}$ & Fuzzy AHP and Fuzzy TOPSIS & Manivel and Ranganathan (2019) \\
\hline 2020 & $\begin{array}{l}\text { Sustainable supplier selection } \\
\text { for the healthcare industry }\end{array}$ & $\begin{array}{l}\text { Measurement of Alternatives and } \\
\text { Ranking according to } \\
\text { COmpromise Solution (MARCOS) }\end{array}$ & Stevic et al. (2020) \\
\hline 2021 & $\begin{array}{l}\text { Evaluation of urban public } \\
\text { health care quality }\end{array}$ & Fuzzy TOPSIS & Khambhati et al. (2021) \\
\hline 2020 & $\begin{array}{l}\text { Supplier selection for Vendor } \\
\text { Managed Inventory (VMI) in } \\
\text { healthcare industry }\end{array}$ & $\begin{array}{l}\text { (i) Fuzzy Delphi approach } \\
\text { (ii) Fuzzy Step-wise Weight } \\
\text { Assessment Ration Analysis } \\
\text { (SWARA) } \\
\text { (iii) Fuzzy Complex Proportional } \\
\text { Assessment of Alternatives } \\
\text { (COPRAS) }\end{array}$ & Sumrit (2020) \\
\hline 2020 & $\begin{array}{l}\text { Supplier evaluation in the } \\
\text { public healthcare system }\end{array}$ & $\begin{array}{l}\text { (i) Making Trial and Evaluation } \\
\text { Laboratory (DEMATEL) } \\
\text { (ii) Best Worst Method (BWM) } \\
\text { (iii) Evaluation based on distance } \\
\text { from average solution (EDAS) }\end{array}$ & Yazdani et al. (2020) \\
\hline 2020 & Supplier selection for hospitals & $\begin{array}{l}\text { Artificial neural network and fuzzy } \\
\text { VIKOR }\end{array}$ & Bahadori et al. (2020) \\
\hline 2021 & $\begin{array}{l}\text { Evaluation of a Chinese } \\
\text { healthcare facility's suppliers }\end{array}$ & The Ordinal Priority Approach & The current study \\
\hline
\end{tabular}


Table 2. Sets, indexes, and variables for the OPA

\begin{tabular}{|c|c|}
\hline \multicolumn{2}{|l|}{ Sts } \\
\hline I & Set of experts $\forall i \in \mathrm{I}$ \\
\hline $\mathrm{J}$ & Set of criteria $\forall j \in \mathrm{J}$ \\
\hline $\mathrm{K}$ & Set of alternatives $\forall k \in \mathrm{K}$ \\
\hline \multicolumn{2}{|l|}{ Indexes } \\
\hline$i$ & Index of the experts $(1, \ldots, p)$ \\
\hline$j$ & Index of preference of the criteria $(1, \ldots, n)$ \\
\hline$k$ & Index of the alternatives $(1, \ldots, m)$ \\
\hline \multicolumn{2}{|c|}{ Variables } \\
\hline Z & The objective function \\
\hline$W_{i j k}^{r}$ & Weight (importance) of $k^{\text {th }}$ alternative based on $j^{\text {th }}$ criterion by $i^{\text {th }}$ expert at $r^{\text {th }}$ rank \\
\hline \multicolumn{2}{|r|}{ 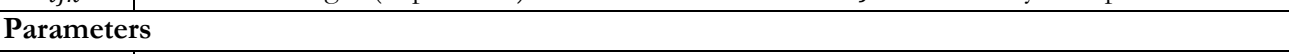 } \\
\hline$i$ & The rank of expert $i$ \\
\hline$j$ & The rank of criterion $j$ \\
\hline$r$ & The rank of alternative $k$ \\
\hline
\end{tabular}

\section{Ordinal Priority Approach}

Attributes, alternatives, and experts (respondents) are key components of any decision-making problem. The Ordinary Priority Approach (OPA) is a linear programming-based approach proposed by Ataei et al. (2020) to help decision-makers solve complex problems using preferential relations. It is an emerging technique of multi-criteria decision-making, and within a short period, it has seen several successful applications in various fields. The OPA has several advantages over other MCDM models as it does not require pairwise comparisons, normalization of data, completeness of data (Mahmoudi et al., 2020). Also, the extended versions of the OPA can further assist the decision-makers in solving problems containing uncertainty (Shajedul, 2021; Mahmoudi et al., 2021a).

In the current study, the OPA was used to estimate the weights of criteria, experts and suppliers. In the current section, the computation steps of the OPA are concisely explained. In Table 2 essential parameters of the OPA are defined. Guided by the literature (Mahmoudi et al., 2021b; Ataei et al., 2020), the relevant steps of the OPA are shown below.

Step 1: Identification of criteria and sub-criteria for supplier selection.

Step 2: The ordinal preference of criteria and sub-criteria should be defined.

Step 3: The linear model (1) should be formed, which is based on collected data from the steps 1 to 2, and later the model can be solved by using an appropriate software (e.g., LINGO, MATLAB, Python, etc.).

$\operatorname{Max} Z$

s.t.

$Z \leq i\left(j\left(r\left(W_{i j k}^{r}-W_{i j k}^{r+1}\right)\right)\right) \quad \forall i, j, k$ and $r$

$Z \leq i j m W_{i j k}^{m} \quad \forall i, j$ and $k$

$\sum_{i=1}^{p} \sum_{j=1}^{n} \sum_{k=1}^{m} W_{i j k}=1$

$W_{i j k} \geq 0 \quad \forall i, j$ and $k$

where $Z$ : Unrestricted in sign

After solving the model, Eq. (2) should be employed to determine the weights of suppliers. 


$$
W_{k}=\sum_{i=1}^{p} \sum_{j=1}^{n} W_{i j k} \quad \forall k
$$

In order to determine the weights of criteria, Eq. (3) should be employed.

$$
W_{j}=\sum_{i=1}^{p} \sum_{k=1}^{m} W_{i j k} \quad \forall j
$$

In order to calculate the weights of experts, Eq. (4) should be utilized.

$$
W_{i}=\sum_{j=1}^{n} \sum_{k=1}^{m} W_{i j k} \quad \forall i
$$

Later, these weights can be used for decision-making and ranking of criteria, experts and the suppliers.

\section{Research Methodology}

Based on the problem (Figure 1), data was gathered from three respondents working in the procurement department of a private healthcare facility in Nanjing, China. To maintain privacy, suppliers were classified as follows: first supplier (A1), second supplier (A2), third supplier (A3), and fourth supplier (A4). Those suppliers were evaluated with which all respondents were familiar. Each respondent was at least a college graduate. Judgments by the experts were primarily based on four criteria, namely delivery performance (C1), cost (C2), quality of the product (C3), and service level (C4), where criteria $\mathrm{C} 1, \mathrm{C} 3$, and $\mathrm{C} 4$ are positive criteria and $\mathrm{C} 2$ being a negative criterion. The data collected is shown in Tables 3 and 4 . In these tables, 1, 2, 3 and 4 imply $1^{\text {st }}$ Priority, $2^{\text {nd }}$ Priority, $3^{\text {rd }}$ Priority, and $4^{\text {th }}$ Priority. The Ordinal Priority Approach will be used for the evaluation of the suppliers. The benefit of using the OPA model is that one can avoid the normalization of data, e.g., one can ignore which criteria were higher-the-better and which were lower the better as the objects are evaluated based on their relative priority (Mahmoudi et al., 2020b).

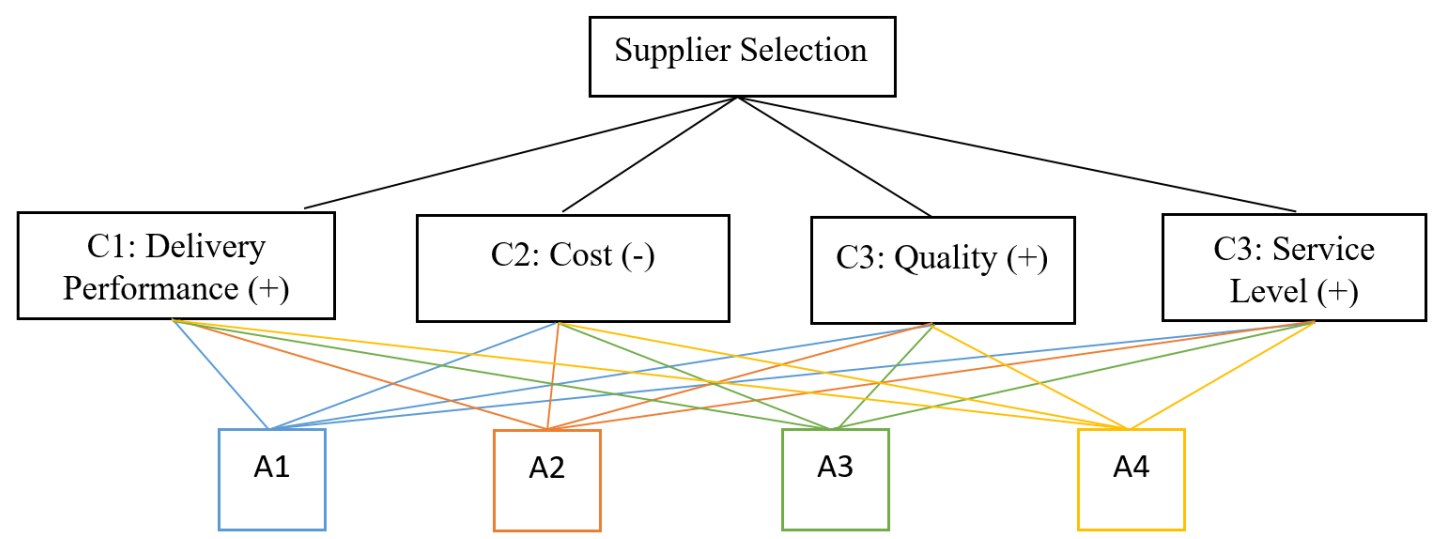

Figure 1. The evaluation of four suppliers of a healthcare facility against four criteria

\section{Results}

The Ordinal Priority Approach was executed as per the steps mentioned before. After solving the OPA model, the weights of experts, criteria, and suppliers were obtained using Eqs. (2) - (4). Later, they were ranked in ascending order, where higher weight means higher rank. Table 4 shows the weights and the ranking of experts. Tables 5 shows the weights and ranking of the experts, criteria and suppliers. 
Table 3. The relative importance of criteria

\begin{tabular}{|c|c|c|c|c|}
\hline & $C 1$ & $C 2$ & $C 3$ & $C 4$ \\
\hline$E_{1}$ & 1 & 2 & 1 & 1 \\
\hline$E_{2}$ & 4 & 3 & 1 & 2 \\
\hline$E_{3}$ & 2 & 1 & 1 & 1 \\
\hline
\end{tabular}

Table 4. The relative importance of suppliers against each criterion

\begin{tabular}{|c|c|c|c|c|c|c|c|c|c|c|c|c|}
\hline & \multicolumn{4}{|c|}{ E1 } & \multicolumn{4}{|c|}{ E2 } & \multicolumn{4}{|c|}{ E3 } \\
\cline { 2 - 15 } & $C 1$ & $C 2$ & $C 3$ & $C 4$ & $C 1$ & $C 2$ & $C 3$ & $C 4$ & C1 & C2 & C3 & C4 \\
\hline$A 1$ & 3 & 1 & 2 & 3 & 3 & 1 & 2 & 3 & 1 & 1 & 2 & 2 \\
\hline$A 2$ & 1 & 2 & 1 & 2 & 1 & 2 & 1 & 1 & 1 & 2 & 1 & 1 \\
\hline$A 3$ & 1 & 3 & 2 & 2 & 2 & 1 & 1 & 4 & 2 & 1 & 1 & 3 \\
\hline$A 4$ & 2 & 3 & 1 & 1 & 1 & 3 & 1 & 2 & 1 & 2 & 1 & 1 \\
\hline
\end{tabular}

Table 5. The weights and ranking of the experts, criteria and suppliers using the OPA

\begin{tabular}{|c|c|c|c|}
\hline & & Weight & Rank \\
\hline \multirow{3}{*}{ Experts } & E1 & 0.354031 & 2 \\
\cline { 2 - 4 } & E2 & 0.242539 & 3 \\
\cline { 2 - 4 } & E3 & 0.403431 & 3 \\
\hline \multirow{4}{*}{ Criteria } & $C 1$ & 0.210978 & 4 \\
\cline { 2 - 4 } & $C 2$ & 0.179760 & 1 \\
\cline { 2 - 4 } & $C 3$ & 0.345798 & 2 \\
\cline { 2 - 4 } & $C 4$ & 0.263465 & 1 \\
\hline \multirow{5}{*}{ Suppliers } & $A 1$ & 0.176672 & 3 \\
\cline { 2 - 4 } & $A 2$ & 0.307376 & 2 \\
\cline { 2 - 4 } & $A 3$ & 0.231218 & \\
\cline { 2 - 4 } & $A 4$ & 0.284734 & \\
\hline
\end{tabular}

Overall, A2 stands out as the best supplier, followed by A4, A3, and then A1, as shown in Figure 2. Therefore, a long-term relationship with the second supplier is more likely to payoff to the healthcare facility than other suppliers. The first supplier should be avoided, and its services should only be obtained when no better supplier is available.

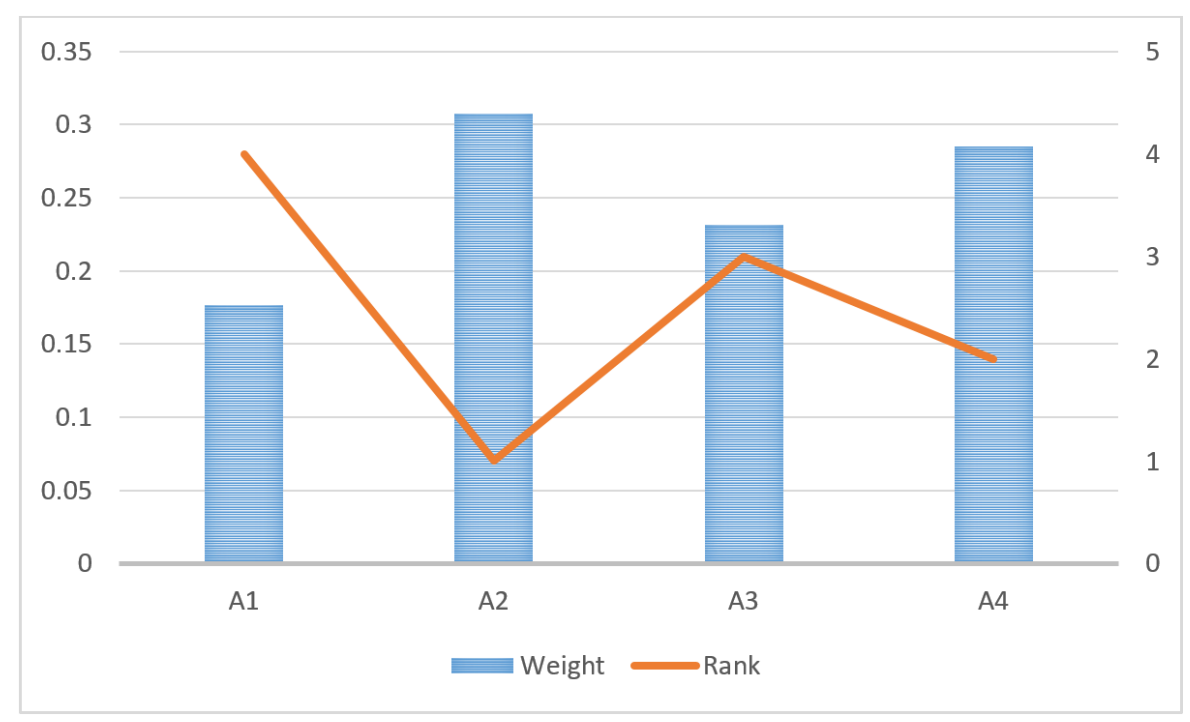

Figure 2. Ranking of the suppliers through the OPA

\section{Conclusion and recommendations}

The reliability of a supply chain is dependent on reliable suppliers. In the healthcare sector, highperforming supplier selection is very crucial for decision-makers. The Ordinal Priority Approach (OPA) is a breakthrough technique for multi-criteria decision-making (MCDM) with a promising future. The current study made pioneering attempts to evaluate and select suppliers for the healthcare industry using 
the OPA method. The OPA method that has many advantages as compared to other existing MCDM technique. The OPA method enjoys a high level of flexibility in dealing with uncertainty in decisionmaking problems and does not need any standardization of incommensurable criteria, which is the major concern for almost every MCDM technique. After evaluating all criteria and extracting the local and global ranking, the result suggests that the fourth supplier should be selected to minimize the overall negative effect and maximize the supply chain surplus.

Every methodology has its shortcomings. In the future, the role of subjective and linguistic variables can be considered to improve the results further. Also, while benefiting from other emerging operations research techniques, the OPA method should be applied in other decision-making problems to find its further strengths and limitations. For instance, the integration of the OPA into other methods can be carried out to evaluate the relative performance of suppliers to the healthcare sector. Since there are various factors related to the healthcare sector, such as patient care, delivery, quality, price, risk management, etc. These factors can affect the healthcare delivery system and its relation to suppliers and, in the long run, more importantly, can influence overall healthcare supply chain surplus. In the future, more criteria can be included in the problem.

\section{References}

Akcan, S., \& Güldeş, M. (2019). Integrated multi-criteria decision-making methods to solve supplier selection problem: a case study in a hospital. Journal of Healthcare Engineering, 2019, Article ID 5614892 https://doi.org/10.1155/2019/5614892

Ataei, Y., Mahmoudi, A., Feylizadeh, M. R., \& Li, D. F. (2020). Ordinal priority approach (OPA) in multiple attribute decision-making. Applied Soft Computing, 86, 105893. https://doi.org/10.1016/j.asoc.2019.105893

Bahadori, M., Hosseini, S. M., Teymourzadeh, E., Ravangard, R., Raadabadi, M., \& Alimohammadzadeh, K. (2020). A supplier selection model for hospitals using a combination of artificial neural network and fuzzy VIKOR. International Journal of Healthcare Management, 13(4), 286-294. https://doi.org/10.1080/20479700.2017.1404730

Fan, Y., Liu, S., Liu, J., Javed, S. A., \& Fang, Z. (2020). Habit or Utility: A Key Choice Point in Promoting the Adoption of Telehealth in China. Complexity, 2020, Article ID 5063756 https://doi.org/10.1155/2020/5063756

Fashoto, S. G., Akinnuwesi, B., Owolabi, O., \& Adelekan, D. (2016). Decision support model for supplier selection in healthcare service delivery using analytical hierarchy process and artificial neural network. African Journal of Business Management, 10(9), 209-232. https://doi.org/10.5897/AJBM2016.803

Ghadimi, P., \& Heavey, C. (2014). Sustainable supplier selection in medical device industry: toward sustainable manufacturing. Procedia Cirp, 15, 165-170. https://doi.org/10.1016/j.procir.2014.06.096

Ishtiaq, P., Khan, S. A., \& Haq, M. U. (2018). A multi-criteria decision-making approach to rank supplier selection criteria for hospital waste management: A case from Pakistan. Waste Management \& Research, 36(4), 386-394. https://doi.org/10.1177/0734242X18755894

Javed, S. A., Liu, S., Mahmoudi, A., \& Nawaz, M. (2019). Patients' Satisfaction and Public and Private Sectors' Healthcare Service Quality in Pakistan: Application of Grey Decision Analysis approaches. International Journal of Health Planning and Management, 34(1), e168-e182. https://doi.org/10.1002/hpm.2629

Khambhati, R., Patel, H., \& Kumar, S. (2021). A performance evaluation and comparison model for Urban Public Healthcare Service Quality (UrbPubHCServQual) by Fuzzy TOPSIS Method. Journal of Nonprofit \& Public Sector Marketing, 1-20. https://doi.org/10.1080/10495142.2020.1865232

Lambert, D. M., Adams, R. J., \& Emmelhainz, M. A. (1997). Supplier Selection Criteria in the Healthcare Industry: A Comparison of Importance and Performace. International Journal of Purchasing and Materials Management, 33(4), 16-22. https://doi.org/10.1111/j.1745-493X.1997.tb00021.x

Mahmoudi, A., Deng, X., Javed, S. A., \& Yuan, J. (2020). Large-Scale Multiple Criteria Decision-Making with Missing Values: Project Selection through TOPSIS-OPA. Journal of Ambient Intelligence and Humanized Computing. https://doi.org/10.1007/s12652-020-02649-w

Mahmoudi, A., Deng, X., Javed, S. A., \& Zhang, N. (2021b). Sustainable Supplier Selection in Megaprojects through Grey Ordinal Priority Approach. Business Strategy and The Environment, 30, 318-339. https://doi.org/10.1002/bse.2623

Mahmoudi, A., Javed, S. A., \& Mardani, A. (2021a). Gresilient Supplier Selection through Fuzzy Ordinal Priority Approach: Decision-making in Post-COVID era. Operations Management Research. https://doi.org/10.1007/s12063-021-00178-z

Ortíz, M. A., Felizzola, H. A., \& Isaza, S. N. (2015). A contrast between DEMATEL-ANP and ANP methods for six sigma project selection: a case study in healthcare industry. BMC Medical Informatics and Decision Making, 15(3), 1-12. https://doi.org/10.1186/1472-6947-15-S3-S3 
Reuter, C., Goebel, P., \& Foerstl, K. (2012). The impact of stakeholder orientation on sustainability and cost prevalence in supplier selection decisions. Journal of Purchasing and Supply Management, 18(4), 270-281. https://doi.org/10.1016/j.pursup.2012.06.004

Saetta, S., Caldarelli, V., Saetta, S., \& Caldarelli, V. (2020). How to increase the sustainability of the agri-food supply chain through innovations in 4.0 perspective: a first case study analysis. Procedia Manufacturing, 42, 333-336. https://doi.org/10.1016/j.promfg.2020.02.083

Şahin, T., Ocak, S., \& Top, M. (2019). Analytic hierarchy process for hospital site selection. Health Policy and Technology, 8(1), 42-50. https://doi.org/10.1016/j.hlpt.2019.02.005

Shajedul, I. (2021). Evaluation of Low-Carbon Sustainable Technologies in Agriculture Sector through Grey Ordinal Priority Approach. International Journal of Grey Systems, 1(1), 5-26. https://doi.org/10.52812/ijgs.3

Stević, Ž., Pamučar, D., Puška, A., \& Chatterjee, P. (2020). Sustainable supplier selection in healthcare industries using a new MCDM method: Measurement of alternatives and ranking according to COmpromise solution (MARCOS). Computers \& Industrial Engineering, 140, 106231. https://doi.org/10.1016/j.cie.2019.106231

Sumrit, D. (2020). Supplier selection for vendor-managed inventory in healthcare using fuzzy multi-criteria decision-making approach. Decision Science Letters, 9(2), 233-256. https://doi.org/10.5267/j.dsl.2019.10.002

Suraraksa, J., \& Shin, K. S. (2019). Comparative Analysis of Factors for Supplier Selection and Monitoring: The Case of the Automotive Industry in Thailand. Sustainability, 11(4), 981. https://doi.org/10.3390/su11040981

Venkatesh, V. G., Dubey, R., Joy, P., Thomas, M., Vijeesh, V., \& Moosa, A. (2015). Supplier selection in blood bags manufacturing industry using TOPSIS model. International Journal of Operational Research, 24(4), 461-488. https://doi.org/10.1504/IJOR.2015.072725

Yazdani, M., Torkayesh, A. E., \& Chatterjee, P. (2020). An integrated decision-making model for supplier evaluation in public healthcare system: the case study of a Spanish hospital. Journal of Enterprise Information Management, 33(5), 965-989. https://doi.org/10.1108/JEIM-09-2019-0294 